\title{
Photochemical oxidation of methyldiethanolamine (MDEA) in aqueous solution by $\mathrm{UV} / \mathrm{K}_{2} \mathrm{~S}_{2} \mathrm{O}_{8}$ process
}

\author{
G. Samira Molareza ${ }^{1}$ Mojtaba Ahmadi ${ }^{1}$ A. A. Zinati Zadeh ${ }^{2}$
}

Received: 7 October 2014/ Accepted: 3 January 2016/Published online: 25 February 2016

(c) The Author(s) 2016. This article is published with open access at Springerlink.com

\begin{abstract}
Methyldiethanolamine (MDEA) as an organic material is a hazardous contaminant in the aquatic environment because of its adverse effects on aquatic life, environment, and humans. In this study, a batch reactor of ultraviolet (UV) light and peroxydisulfate was performed to investigate the degradation of MDEA in aqueous media. The effect of different experimental parameters such as UV irradiation, peroxydisulfate concentration, MDEA concentration, temperature, and solution $\mathrm{pH}$ on removal of MDEA was evaluated precisely. No significant degradation was observed with a separate UV light. Adding peroxydisulfate to the solution increased the removal performance more than $75 \%$.
\end{abstract}

Keywords Peroxydisulfate $\cdot$ MDEA $\cdot$ Advanced oxidation processes . Wastewater treatment

\section{Introduction}

Raw natural gas includes some acidic gases such as $\mathrm{H}_{2} \mathrm{~S}$ and $\mathrm{CO}_{2}$. These acidic gases are very corrosive and toxic to the environment, and therefore required to be removed. Different alkanolamines such as monoethanolamine (MEA), diethanolamine (DEA), methyldiethanolamine (MDEA) and diisopropanolamine (DIPA) are used for the removal of acidic gases in the sweetening gas units [1]. In

Mojtaba Ahmadi

m_ahmadi@razi.ac.ir

1 Chemical Engineering Department, Faculty of Engineering, Razi University, Kermanshah, Iran

2 Applied Chemistry Department, Faculty of Chemistry, Razi University, Kermanshah, Iran addition $N$-methyldiethanolamine (MDEA) as metalMDEA complexes have as propertysignificant ultraviolet (UV) absorption. New photosensitive precursors was prepared as thin films by $\mathrm{N}$-methyldiethanolamine complex [2, 3]. Usually during cleaning, protecting and scheduled control of absorption and desorption column, high concentration of alkanolamine is generated into the wastewater [4]. Nevertheless, due to its toxicity the conventional biological treatment cannot be used for this wastewater [5].

During recent two decades, advanced oxidation processes (AOPs) have been considered as popular techniques to treat the high concentration of organic contaminant in the wastewater [6]. AOPs are of the most alternative techniques for destruction of many other organic matters in wastewater and effluents. These processes generally involve $\mathrm{UV} / \mathrm{H}_{2} \mathrm{O}_{2}, \mathrm{UV} / \mathrm{O}_{3}, \mathrm{UV} / \mathrm{S}_{2} \mathrm{O}_{8}{ }^{2-}$ or UV/Fenton's reagent for degradation of contaminants [7-9].

A large number of experimental works have been performed on the application of AOPs to treat wastewater. The Fenton' reagent in the AOPs was used to degrade MEA [10], DEA [11], $N, N$-diethyl-p-phenylenediamine [12] and DIPA [13]. Also, the use of $\mathrm{UV} / \mathrm{H}_{2} \mathrm{O}_{2}$ in the AOPs for degradation of MEA and MDEA [4, 14] and ozonation for degradation of DEA [15] have been studied.

Because of its high reactivity of $\mathrm{UV} / \mathrm{S}_{2} \mathrm{O}_{8}{ }^{2-}$ process, high solubility, relatively low cost of peroxydisulfate and benign end products, recently the application of UV/ $\mathrm{S}_{2} \mathrm{O}_{8}{ }^{2-}$ in wastewater treatment was investigated in numerous studies [16]. Peroxydisulfate $\left(\mathrm{S}_{2} \mathrm{O}_{8}{ }^{2-}\right)$ is a strong oxidant $\left(E_{0}=2.05 \mathrm{~V}\right)$ which has been used widely in the petroleum industry for the treatment of hydraulic fluids or as a reaction initiator [17].

It has also been reported to be effective for degrading organic matters in hazardous wastewaters in acidic or basic 
media through direct chemical oxidation, where peroxydisulfate is used as a sacrificial reagent [17-19]. However, since the reactions of peroxydisulfate are generally slow at normal temperature. The thermal or photochemical activated decomposition of $\mathrm{S}_{2} \mathrm{O}_{8}{ }^{2-}$ ion to $\mathrm{SO}_{4}^{\circ-}$ radical has been proposed as a method of accelerating the process [19, 20], as summarized in the following reactions (Eqs. 1-12):

$$
\begin{aligned}
& \mathrm{S}_{2} \mathrm{O}_{8}^{2-} \stackrel{\text { hv heat }}{\longrightarrow} 2 \mathrm{SO}_{4}^{\circ-} \\
& \mathrm{SO}_{4}^{\circ-}+\mathrm{RH}_{2} \rightarrow \mathrm{SO}_{4}^{2-}+\mathrm{H}^{+}+\mathrm{RH}^{\circ} \\
& \mathrm{RH}^{\circ}+\mathrm{S}_{2} \mathrm{O}_{8}^{2-} \rightarrow \mathrm{R}+\mathrm{SO}_{4}^{2-}+\mathrm{H}^{+}+\mathrm{SO}_{4}^{\circ-} \\
& \mathrm{SO}_{4}^{\circ-}+\mathrm{RH} \rightarrow \mathrm{R}^{\circ}+\mathrm{SO}_{4}^{2-}+\mathrm{H}^{+} \\
& 2 R \rightarrow R R(\operatorname{dim} e r) \\
& \mathrm{SO}_{4}^{\circ-}+\mathrm{H}_{2} \mathrm{O} \rightarrow \mathrm{HSO}_{4}^{-}+\mathrm{OH}^{\circ}\left(500 \pm 60 \mathrm{~S}^{-1}\right) \\
& \mathrm{HSO}_{4}^{-} \rightarrow \mathrm{H}^{+}+\mathrm{SO}_{4}^{2-} \\
& \mathrm{OH}^{\circ}+\mathrm{S}_{2} \mathrm{O}_{8}^{2-} \rightarrow \mathrm{HSO}_{4}^{-}+\mathrm{SO}_{4}^{\circ-}+\frac{1}{2} \mathrm{O}_{2} \\
& \mathrm{SO}_{4}^{\circ-}+\mathrm{OH}^{\circ} \rightarrow \mathrm{HSO}_{4}^{-}+\frac{1}{2} \mathrm{O}_{2} \\
& 2 \mathrm{OH}^{\circ} \rightarrow \mathrm{H}_{2} \mathrm{O}_{2}(\text { expect in alkaline solution}) \\
& \mathrm{H}_{2} \mathrm{O}_{2} \rightarrow \mathrm{H}_{2} \mathrm{O}+\frac{1}{2} \mathrm{O}_{2}(\text { mostly in acidic solution }) \\
& \mathrm{S}_{2} \mathrm{O}_{8}^{2-}+\mathrm{H}_{2} \mathrm{O}_{2} \rightarrow 2 \mathrm{H}^{+}+2 \mathrm{SO}_{4}^{2-}+\mathrm{O}_{2}
\end{aligned}
$$

As can be seen in the above reactions, the oxidation process is begun by production of the sulfate and hydroxyl radicals (Eqs. 1 and 2). These radicals are powerful oxidizing agents which may attack the organic matters $(R)$ in the contaminated water. It causes, ultimately, complete decomposition of toxic and bioresistant compounds to harmless species (like $\mathrm{CO}_{2}, \mathrm{H}_{2} \mathrm{O}$, etc.). Sulfate ion will be generated as the end product, which is practically inert and is not considered to be a pollutant. It is worth to mention that the United States Environmental Protection Agency (USEPA) has listed $\mathrm{SO}_{4}{ }^{2-}$ under the secondary drinking water standards. A maximum concentration of sulfate ion is $250 \mathrm{mg} \mathrm{l}^{-1}(1.43 \mathrm{mM})$, based on sanitary reasons such as taste and odor [16, 21].

The peroxydisulfate is normally available as a salt associated with ammonium, sodium, or potassium. The comparative performance of $\mathrm{K}_{2} \mathrm{~S}_{2} \mathrm{O}_{8}$ (KPS) and $\left(\mathrm{NH}_{4}\right)_{2-}$ $\mathrm{S}_{2} \mathrm{O}_{8}$ (APS) as an oxidant under the irradiation of UV light for removal of butylated hydroxyanisole [19], the dye Reactive Yellow 84 [22] and tylosin [23] was investigated. The results have indicated that KPS provides a more rapid photooxidative removal than APS at neutral $\mathrm{pH}$. The difference in the removal efficiency is apparently due to the presence of the ammonium ion. The aqueous ammonium can undergo photooxidation leading to nitrate and/or nitrite by the available oxidants in the solution, such as, $\mathrm{S}_{2} \mathrm{O}_{8}{ }^{2-}$, and its related intermediates $\mathrm{H}_{2} \mathrm{O}_{2}$ or $\mathrm{O}_{2}[19,20]$. Furthermore, the reaction of $\mathrm{NH}^{4+} / \mathrm{NH}_{3}$ with $\mathrm{UV} / \mathrm{S}_{2} \mathrm{O}_{8}{ }^{2-}$ process is proved to be able to convert it to nitrate under the $254 \mathrm{~nm}$ photolysis [24], thereby making the ammonium as a competitor of the organic pollutants. In view of this, and the general unsuitability of adding ammonia to waters, APS is not recommended to be used in the UV/peroxydisulfate oxidation process. Therefore, the UV/KPS combination was chosen for further investigation throughout this study.

It has been proven that $\mathrm{UV} / \mathrm{S}_{2} \mathrm{O}_{8}{ }^{2-}$ and $\mathrm{UV} / \mathrm{H}_{2} \mathrm{O}_{2}$ (the most common process) have similar reaction rate constants [25]. Moreover, peroxydisulfate advantages $\mathrm{UV} / \mathrm{H}_{2} \mathrm{O}_{2}$ and other similar approaches by the following reasons: (1) Peroxydisulfate ions seem to be more useful when the process is not well controlled, for example when overdosing occurs because of the potential quenching effect of using $\mathrm{H}_{2} \mathrm{O}_{2}$ [25]. (2) Peroxydisulfate would be more applicable for industrial uses in comparison to liquid oxidants such as $\mathrm{H}_{2} \mathrm{O}_{2}$, because it is a solid oxidant. (3) Peroxydisulfate salts are much cheaper than other oxidants like hydrogen peroxide and ozone [26-28].

In this study, using $\mathrm{UV} / \mathrm{S}_{2} \mathrm{O}_{8}{ }^{2-}$ process the destruction of MDEA as an amine pollutant from contaminated water was investigated. Moreover, effect of different experimental parameters such as UV irradiation, peroxydisulfate concentration, MDEA concentration, Temperature, and $\mathrm{pH}$ was evaluated.

\section{Experimental}

\section{Reagents}

Potassium peroxydisulfate $\left(\mathrm{K}_{2} \mathrm{~S}_{2} \mathrm{O}_{8}\right)$, sulfuric acid and sodium hydroxide were of laboratory reagent grade (Merck Co., Germany) and used without further purification. The synthetic wastewater for which treatment process was performed contains methyldiethanolamine (MDEA).

\section{General procedure}

Methyldiethanolamine (MDEA) degradation experiments were conducted in a photoreactor. For UV/peroxydisulfate process, irradiation was carried out with a 125 and $250 \mathrm{~W}$ (UV-C) mercury lamp (Philips, the Netherland), which was put above a batch photoreactor. The distance between the solution and UV source was adjusted according to the experimental conditions. The volume of sample was $500 \mathrm{ml}$, and total time of experiment was $60 \mathrm{~min}$. The 
reactor had a water-flow jacket for regulating the temperature by means of an external circulating flow of a thermostat. Since the photocatalysis is sustained by a ready supply of dissolved oxygen, air was supplied to the reaction system at a constant flow rate using a micro-air compressor.

Dilute solutions of sodium hydroxide and sulfuric acid were used for $\mathrm{pH}$ adjustment and the initial $\mathrm{pH}$ values were measured by Metrohm $827 \mathrm{pH} / \mathrm{LF}$ portable $\mathrm{pH} / \mathrm{con}-$ ductivity-meter, Schott Instruments GmbH, Mainz, Germany. A prepared solution was transferred to the reactor and after adjusting the temperature, the UV lamp was switched on to initiate the process. During the experiments a mild aeration was kept for mixing the content and saturation with $\mathrm{O}_{2}$. Samples $(6 \mathrm{ml})$ were taken at regular time intervals. A maximum total sampling volume of $24 \mathrm{ml}$ was withdrawn during each experimental run which is not significant, compared with the solution volume. Chemical oxygen demand (COD) was measured by a closed reflux and titrimetric method. Using this method, the degradation efficiency $(X)$ was obtained at any time, according to [28]:

$X=\frac{C_{0}-C}{C_{0}}$

where $C_{0}$ and $C$ are initial and appropriate concentrations of MDEA at any time.

Peroxydisulfate concentration varied from 5 to $25 \mathrm{mM}$, while MDEA concentration varied from 500 to $1500 \mathrm{ppm}$ and temperature varied from 30 to $50{ }^{\circ} \mathrm{C}$. The effect of $\mathrm{pH}$ was evaluated in the range of $2-10$. Figure 1 shows a schematic view of the reactor and its belongings.

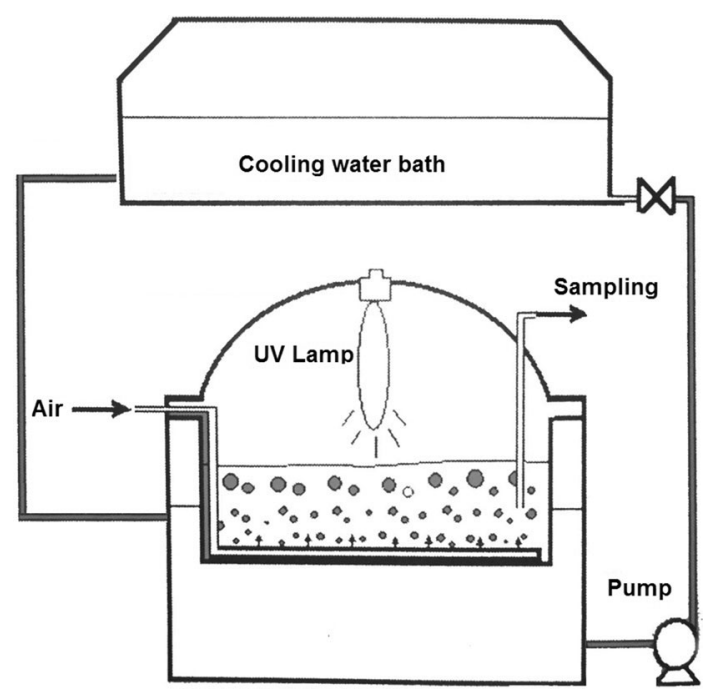

Fig. 1 The schematic view of the photo reactor set-up

\section{Results and discussion}

\section{Effect of peroxydisulfate and UV irradiation on degradation of MDEA}

Degradation of MDEA was investigated with UV irradiation only, $\mathrm{S}_{2} \mathrm{O}_{8}{ }^{2-}$ without $\mathrm{UV}$ radiation, and $\mathrm{UV}$ radiation plus $\mathrm{S}_{2} \mathrm{O}_{8}{ }^{2-}$ with concentrations of $25 \mathrm{mM}$ peroxydisulfate, $500 \mathrm{ppm}$ MDEA and $\mathrm{pH}=8.5$. In the first case without any peroxydisulfate, we found no degradation, while using peroxydisulfate without UV irradiation, approximately, the degradation of $6 \%$ was attained. However, UV plus peroxydisulfate made the two mentioned cases more efficient notably by $75 \%$ removal (Fig. 2). In fact, UV irradiation improved the reaction of peroxydisulfate through intensifying the formation of hydroxyl and sulfate radicals in comparison with slow activity at normal temperature. Therefore, as summarized in Eqs. 1-5, thermo-photochemical treatments activated decomposition of $\mathrm{S}_{2} \mathrm{O}_{8}{ }^{2-}$ ion to $\mathrm{SO}_{4}{ }^{-}$radical which has been proven by acceleration of the process [29]. A rapid attack can be produced on any oxidizable agent including organic pollutants (e.g., MDEA) once $\mathrm{SO}_{4}^{\circ-}$ is formed [30]. Also, available oxidants in the solution and their corresponding intermediates are showed in Eqs. 6-12. Similar observations have been reported by others [31]. Chan et al showed that the removal of iopromide with photo-activated potassium peroxydisulfate was $90 \%$ and it was achieved in 30 min under a light intensity of 6 lamps.

Both $\mathrm{SO}_{4}^{\circ-}$ and $\mathrm{OH}^{\circ}$ are possibly cause of the degradation of organic contaminants. Meanwhile either radical may predominate over the other depending on $\mathrm{pH}$ conditions, and react with organic compounds commonly by three mechanisms: hydrogen abstraction, hydrogen addition, and electron transfer.

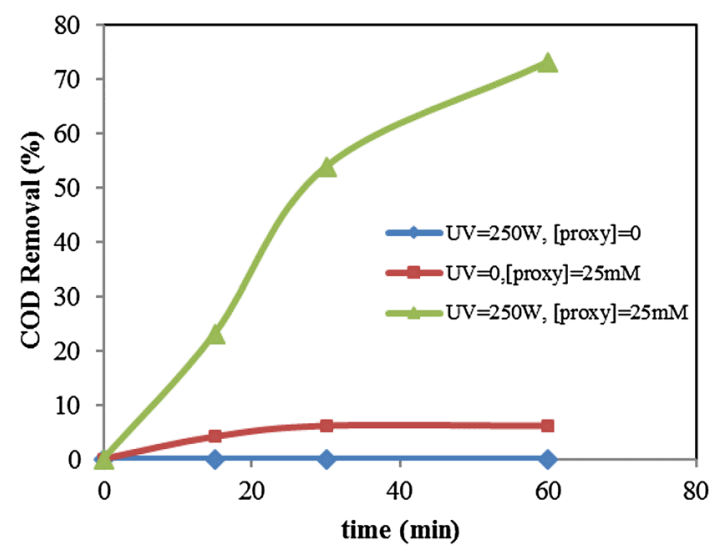

Fig. 2 Effect of peroxydisulfate and UV irradiation on degradation of MDEA (MDEA concentration, $500 \mathrm{ppm}$; temperature, $30{ }^{\circ} \mathrm{C}$ ) 
Sulfate radicals show a higher standard reduction potential than hydroxyl radicals at neutral $\mathrm{pH}$, and both radicals show similar reduction potentials under acidic conditions [27]. In general, $\mathrm{SO}_{4}^{\circ-}$ is more likely to participate in electron transfer reactions, whereas $\mathrm{OH}^{\circ}$ is more likely to participate in hydrogen abstraction or addition reactions [32].

\section{Effect of initial MDEA concentration}

The initial MDEA concentration has a remarkable effect on degradation of MDEA in the $\mathrm{UV} / \mathrm{S}_{2} \mathrm{O}_{8}{ }^{2-}$ process. Investigations were made by varying the concentration of MDEA from 500 to $1500 \mathrm{ppm}$ at fixed initial $\mathrm{S}_{2} \mathrm{O}_{8}{ }^{2-}$ concentration of $15 \mathrm{mM}, \mathrm{pH}=8.5$, irradiation of $125 \mathrm{~W}$ and temperature of $30{ }^{\circ} \mathrm{C}$. Degradation of $50 \%$ is observed in 500 ppm, while only $19 \%$ of degradation is achieved in $1500 \mathrm{ppm}$ concentration of MDEA. The effect of initial MDEA concentration on photooxidation efficiency has been depicted in Fig. 3. As shown in Fig. 3, the higher concentration of MDEA was, the lower the degradation rate would be. This is because the rising in MDEA concentration induces an inner filter effect and hence the solution becomes more and more impermeable to UV radiation [33]. Also, the increase in MDEA concentration decreases the ratio of hydroxyl radical to MDEA and percentage of degradation reduces in result.

\section{Effect of initial peroxydisulfate concentration}

The initial concentration of peroxydisulfate was found to be an important parameter for the photooxidative degradation of MDEA in the $\mathrm{UV} / \mathrm{S}_{2} \mathrm{O}_{8}{ }^{2-}$ process. The effect of initial $\mathrm{S}_{2} \mathrm{O}_{8}{ }^{2-}$ concentration on photooxidation efficiency has been expressed in Fig. 4.

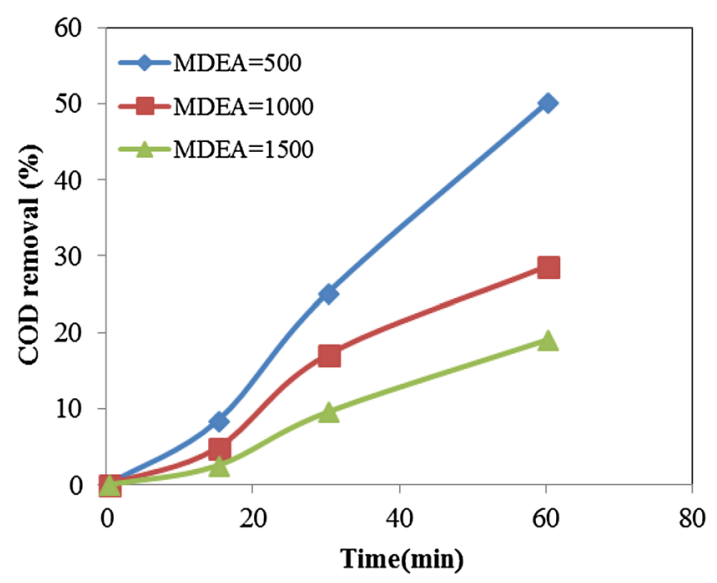

Fig. 3 Effect of the initial MDEA concentration on the oxidative degradation of MDEA (peroxydisulfate concentration, $15 \mathrm{mM}$; temperature, $30{ }^{\circ} \mathrm{C}$; UV, $125 \mathrm{~W}$ )

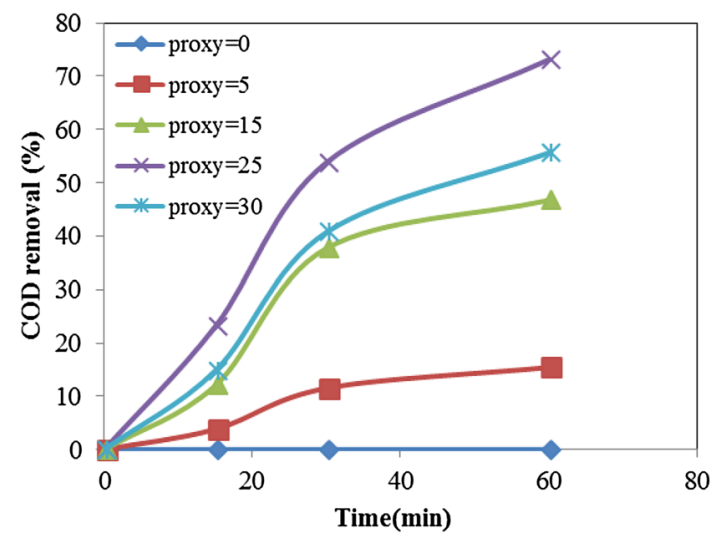

Fig. 4 Effect of the initial peroxydisulfate concentration on the degradation of MDEA (MDEA concentration, $500 \mathrm{ppm}$; temperature, $30{ }^{\circ} \mathrm{C}$; UV, $250 \mathrm{~W}$ )

Investigations were made using varying the concentration of $\mathrm{S}_{2} \mathrm{O}_{8}{ }^{2-}$ from 5 to $25 \mathrm{mM}$ at fixed initial MDEA concentration of $500 \mathrm{ppm}, \mathrm{pH}=8.5$, irradiation of $250 \mathrm{~W}$ and temperature of $30{ }^{\circ} \mathrm{C}$. Studies have revealed that increase in amount of $\mathrm{S}_{2} \mathrm{O}_{8}{ }^{2-}$ from 5 to $25 \mathrm{mM}$ would enhance degradation of the MDEA [34]. These observations can be explained by the fact that the increase in concentration of peroxydisulfate results in higher generation of hydroxyl and sulfate radicals and improves the photooxidative degradation of the MDEA consequently. It is likely because of excessive generation of hydroxyl radicals (Eqs. 1 and 6) that would be recombined to less reactive form of $\mathrm{H}_{2} \mathrm{O}_{2}$ (Eq. 10), which is a known quencher of $\mathrm{OH}^{\circ}$ radical (Eq. 11). Therefore, the destruction of MDEA was slightly slowed down at higher $\mathrm{S}_{2} \mathrm{O}_{8}{ }^{2-}$ dosages. However, such a recombination effect of the radical was likely not very effective due to the low steady-state concentrations of the radicals; higher decay rates of MDEA at higher $\mathrm{S}_{2} \mathrm{O}_{8}{ }^{2-}$ dosages are still expected [20, 34]. For example, Lin et al. investigated the degradation of ciprofloxacin by UV/peroxydisulfate process. They described the removal efficiency increased with an increase for $\mathrm{S}_{2} \mathrm{O}_{8}{ }^{2-}$ [35]. They described the degradation efficiency of ciprofloxacin increased with time, reaching $95 \%$ after $30 \mathrm{~min}$.

The first-order reaction kinetics was used to study the degradation kinetics of MDEA by $\mathrm{UV} / \mathrm{S}_{2} \mathrm{O}_{8}{ }^{2-}$ process. The individual expression was presented as below:

First-order reaction kinetics

$\frac{\mathrm{d} C}{\mathrm{~d} t}=-k_{1} C$

where $C_{t}$ the concentration of MDEA at reaction time $t(\mathrm{mM}), C_{\mathrm{o}}$ the initial concentration of the MDEA $(\mathrm{mM}), k_{1}$ the rate constant of the first-order kinetic equation $\left(\mathrm{min}^{-1}\right)$. 
Regression analysis based on the apparent first-order reaction kinetics for the degradation of MDEA in UV/ $\mathrm{S}_{2} \mathrm{O}_{8}{ }^{2-}$ was conducted and the results are shown in Fig. 5. The apparent first-order rate constant ranged from 0.003 to $0.0224 \mathrm{~min}^{-1}$ (Table 1). $k_{1}$ was increased with increasing initial potassium peroxydisulfate concentration. Similar results were also obtained by former studies [36-38]. Khataee et al. investigated the decolorization of basic blue by UV/peroxydisulfate treatment. They described the decolorization rate constant increased with an increase in the amount of $\mathrm{S}_{2} \mathrm{O}_{8}{ }^{2-}$ [39].

\section{Effect of UV irradiation}

Investigations were made by varying the irradiation of UV from 0 to $250 \mathrm{~W}$ at fixed initial MDEA concentration of $500 \mathrm{ppm}$, initial concentration of $\mathrm{S}_{2} \mathrm{O}_{8}{ }^{2-}, \mathrm{pH}=8.5$ and temperature of $30{ }^{\circ} \mathrm{C}$. The effect of UV light intensity on the degradation of MDEA is shown in Fig. 6. The figure clearly shows that the removal increases through increasing UV irradiation intensity. This increase is due to the enhanced production of sulfate and hydroxyl radicals. At low UV light intensity the rate of photolysis of $\mathrm{S}_{2} \mathrm{O}_{8}{ }^{2-}$ is limited hence degradation increases [20, 40].

\section{Effect of the initial pH}

The effect of initial $\mathrm{pH}$ was investigated in the range of 2-10 with constant concentration of MDEA of $500 \mathrm{ppm}$, initial peroxydisulfate concentration of $15 \mathrm{mM}$, irradiation of $250 \mathrm{~W}$ and temperature of $30{ }^{\circ} \mathrm{C}$. The effect of initial $\mathrm{pH}$ on photooxidation efficiency has been depicted in Fig. 7. The $\mathrm{pH}=5-7$ was found to be the most effective level of $\mathrm{pH}$ in degradation of MDEA. However, effective

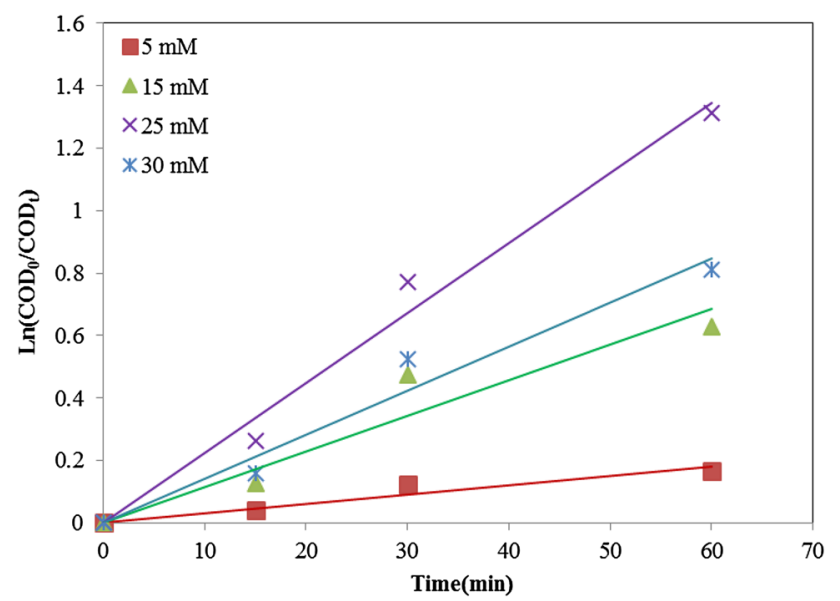

Fig. 5 First-order reaction kinetics for the degradation of MDEA (MDEA concentration, $500 \mathrm{ppm}$; temperature, $30^{\circ} \mathrm{C}$; UV, $250 \mathrm{~W}$ )
Table 1 Rate constants of UV/peroxydisulfate oxidation of MDEA at $30^{\circ} \mathrm{C}$

\begin{tabular}{llll}
\hline Sample number & {$\left[\mathrm{S}_{2} \mathrm{O}_{8}{ }^{2-}\right]_{0}(\mathrm{mM})$} & $\mathrm{UV}(\mathrm{W})$ & $k_{1}\left(\mathrm{~min}^{-1}\right)$ \\
\hline 1 & 5 & 250 & 0.0030 \\
2 & 15 & 250 & 0.0114 \\
3 & 25 & 250 & 0.0224 \\
4 & 30 & 250 & 0.0141 \\
\hline
\end{tabular}

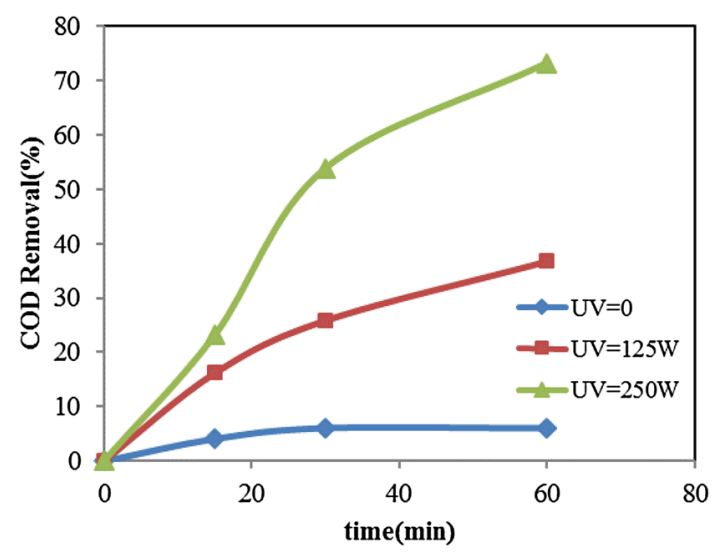

Fig. 6 Effect of UV light irradiation on the degradation of MDEA (MDEA concentration, $500 \mathrm{ppm}$; peroxydisulfate concentration, $15 \mathrm{mM}$; temperature, $30^{\circ} \mathrm{C}$ )

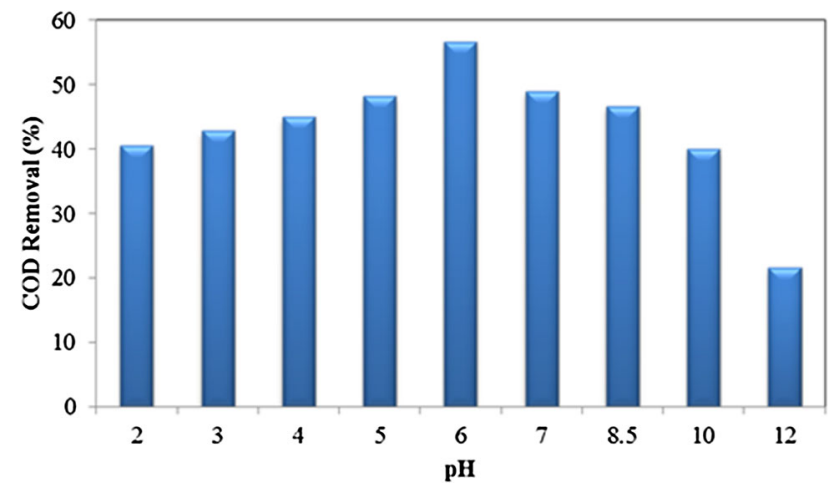

Fig. 7 Effect of $\mathrm{pH}$ on the oxidative degradation of MDEA (MDEA concentration, $500 \mathrm{ppm}$; peroxydisulfate concentration, $15 \mathrm{mM}$; temperature, $30{ }^{\circ} \mathrm{C} ; \mathrm{UV}, 250 \mathrm{~W}$ )

photodegradation of MDEA was observed at all $\mathrm{pH}$ levels, which reveals the efficiency of this method in treatment of wastewater in different regions. The destruction performance increased from low to initial neutral $\mathrm{pH}$ levels, but it started to reduce when basic $\mathrm{pH}$ was performed. The decreasing photo decay at $\mathrm{pH} \geq 7$ can be explained by the following reasons: (a) the instability of $\mathrm{H}_{2} \mathrm{O}_{2}$ at high $\mathrm{pH}$ level, (b) relatively higher amounts of $\mathrm{OH}^{\circ}$ and $\mathrm{SO}_{4}^{\circ-}$ generated catalytically in alkaline conditions, which 
induced recombination of these two radicals (Eq. 9), though this could be minor [19].

Under acidic conditions, more $\mathrm{SO}_{4}^{\circ-}$ can be generated according to Eqs. 14 and 15 [41], which can enhance the degradation efficiency of MDEA. Under alkaline conditions, $\mathrm{SO}_{4}^{\circ-}$ may react with $\mathrm{OH}^{-}$to form $\mathrm{OH}^{\circ}[41,42]$, according to Eq. 16. When the $\mathrm{pH}$ value exceeded 7, a base conversion of $\mathrm{SO}_{4}{ }^{\circ-}$ to $\mathrm{OH}^{\circ}$ made $\mathrm{OH}^{\circ}$ the dominant radical species [41]. $\mathrm{OH}^{\circ}$ may have a very poor reactivity with MDEA in aqueous solutions. Accordingly, under alkaline conditions, $\mathrm{OH}^{-}$may play a role of free radicals scavenger and, resulted in a decrease in the degradation of MDEA. Additionally, carbon oxide formed from the degradation of MDEA could lead to the formation of bicarbonate and carbonate ions under alkaline conditions, which may inhibit the degradation of MDEA [43].

$$
\begin{aligned}
& \mathrm{S}_{2} \mathrm{O}_{8}^{2-}+\mathrm{H}^{+} \rightarrow \mathrm{HS}_{2} \mathrm{O}_{8}^{-} \\
& \mathrm{HS}_{2} \mathrm{O}_{8}^{-} \rightarrow \mathrm{SO}_{4}^{\circ-}+\mathrm{SO}_{4}^{2-}+\mathrm{H}^{+} \\
& \mathrm{SO}_{4}^{\circ-}+\mathrm{OH}^{-} \rightarrow \mathrm{SO}_{4}^{2-}+\mathrm{OH}^{\circ} .
\end{aligned}
$$

\section{Effect of the temperature}

Temperature influence on the used processes was investigated in the range of $30-50{ }^{\circ} \mathrm{C}$. The results for the UV/ $\mathrm{S}_{2} \mathrm{O}_{8}{ }^{2-}$ in constant concentration of MDEA of $500 \mathrm{ppm}$, initial peroxydisulfate concentration of $15 \mathrm{mM}$, irradiation of $250 \mathrm{~W}$ and $\mathrm{pH}=8.5$ are shown in Fig. 8 .

Temperature helps the degradation reaction to compete more effectively according to the Arrhenius equation; however, at the same time, it reduces the oxygen solubility in water which is not desirable [44].

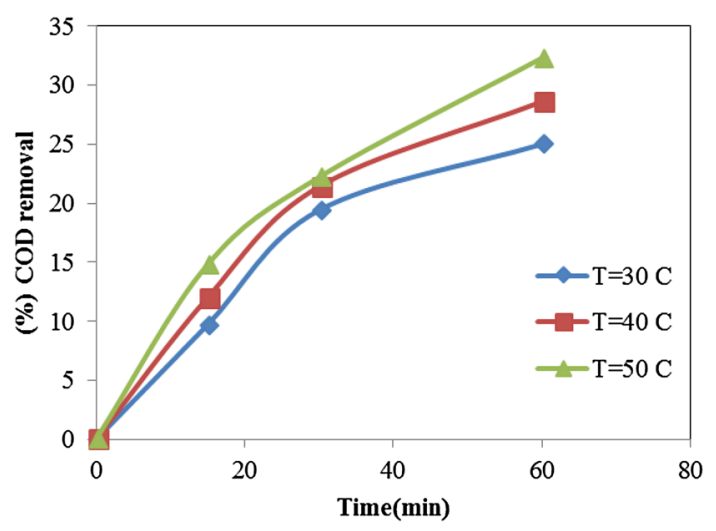

Fig. 8 Effect of the temperature on the oxidative degradation of MDEA (MDEA concentration, $1000 \mathrm{ppm}$; peroxydisulfate concentration, $15 \mathrm{mM}$; UV, $125 \mathrm{~W}$ )

\section{Conclusions}

In this work degradation of MDEA by peroxydisulfate along with UV irradiation is known an effective and safe method was studied. The following conclusions were reached:

- Almost no MDEA removal was achieved using UV irradiation alone and using peroxydisulfate alone removal percentage was obtained about $7 \%$. Finally, more than $75 \%$ of MDEA concentration removed using UV irradiation and peroxydisulfate simultaneously.

- Increase in MDEA concentration would decrease the degradation. For example, the degradation of $50 \%$ was observed in $500 \mathrm{ppm}$, while only degradation of $19 \%$ was obtained in $1500 \mathrm{ppm}$ concentration of MDEA.

- In terms of the changed of peroxydisulfate concentration, i.e., 0 to $25 \mathrm{mM}$, the COD removals increased.

- The COD removal increased as temperature and UV irradiation intensity increased.

- The solution $\mathrm{pH}$ had a major influence on MDEA degradation in the $\mathrm{UV} / \mathrm{K}_{2} \mathrm{~S}_{2} \mathrm{O}_{8}$ process. The range of optimum solution $\mathrm{pH}$ was $6-7$; however, all levels of $\mathrm{pH}$ demonstrate satisfactory removal but these ranges can be better for industrial conditions.

- Increase in the temperature would increase the degradation according to the Arrhenius equation. Increasing UV irradiation intensity increases removal by improving production of sulfate and hydroxyl radicals.

- The optimum operating conditions, which showed that the initial MDEA concentration of $500 \mathrm{ppm}$, UV irradiation of $250 \mathrm{~W}$, initial peroxydisulfate concentration of $25 \mathrm{mM}$, and a temperature of $30^{\circ} \mathrm{C}$ were the best conditions. Under the optimized conditions, the maximum degradation of MDEA was $75 \%$.

Acknowledgments The authors thank the department of chemical engineering in Razi university of Kermanshah, Iran, for financial and other supports.

Open Access This article is distributed under the terms of the Creative Commons Attribution 4.0 International License (http://crea tivecommons.org/licenses/by/4.0/), which permits unrestricted use, distribution, and reproduction in any medium, provided you give appropriate credit to the original author(s) and the source, provide a link to the Creative Commons license, and indicate if changes were made.

\section{References}

1. Kohl AL, Nielsen R (1997) Gas purification. Gulf Professional Publishing, Houston

2. Perez-Mezcua D, Sirera R, Jimenez R, Bretos I, De Dobbelaere C, Hardy A, Van Bael MK, Calzada ML (2014) A UV-absorber 
bismuth(iii)-N-methyldiethanolamine complex as a low-temperature precursor for bismuth-based oxide thin films. J Mater Chem C 2(41):8750-8760

3. Martin-Arbella N, Bretos I, Jimenez R, Calzada ML, Sirera R (2011) Metal complexes with N-methyldiethanolamine as new photosensitive precursors for the low-temperature preparation of ferroelectric thin films. J Mater Chem 21(25):9051-9059

4. Harimurti S, Rahmah A, Omar A, Murugesan T (2011) The degradation mechanism of wastewater containing MDEA using $\mathrm{UV} / \mathrm{H}_{2} \mathrm{O}_{2}$ advanced oxidation process. In: National Postgraduate Conference (NPC), 2011. IEEE, pp 1-5

5. Fürhacker M, Pressl A, Allabashi R (2003) Aerobic biodegradability of methyldiethanolamine (MDEA) used in natural gas sweetening plants in batch tests and continuous flow experiments. Chemosphere 52(10):1743-1748

6. Pera-Titus M, García-Molina V, Baños MA, Giménez J, Esplugas S (2004) Degradation of chlorophenols by means of advanced oxidation processes: a general review. Appl Catal B 47(4):219-256

7. Vilhunen SH, Sillanpää ME (2009) Ultraviolet light emitting diodes and hydrogen peroxide in the photodegradation of aqueous phenol. J Hazard Mater 161(2):1530-1534

8. Daneshvar N, Aber S, Seyed Dorraji M, Khataee A, Rasoulifard M (2007) Photocatalytic degradation of the insecticide diazinon in the presence of prepared nanocrystalline $\mathrm{ZnO}$ powder fs under irradiation of UV-C light. Sep Purif Technol 58(1):91-98

9. Daneshvar N, Rasoulifard M, Khataee A, Hosseinzadeh F (2007) Removal of CI Acid Orange 7 from aqueous solution by UV irradiation in the presence of $\mathrm{ZnO}$ nanopowder. J Hazard Mater 143(1):95-101

10. Harimurti S, Dutta BK, Ariff IFB, Chakrabarti S, Vione D (2010) Degradation of monoethanolamine in aqueous solution by Fenton's reagent with biological post-treatment. Water Air Soil Pollut 211(1-4):273-286

11. Dutta BK, Harimurti S, Ariff IF, Chakrabarti S, Vione D (2010) Degradation of diethanolamine by Fenton's reagent combined with biological post-treatment. Desalination Water Treat 19(1-3):286-293

12. Pachamuthu MP, Karthikeyan S, Sekaran G, Maheswari R, Ramanathan A (2014) Fenton-type oxidative degradation of $N, N$ diethyl-p-phenyl diamine by a mesoporous wormhole structured FeTUD-1 catalyst. Clean 43(3):375-381

13. Omar AA, Ramli RM, Khamaruddin PNFM (2010) Fenton oxidation of natural gas plant wastewater. Can J Chem Eng Technol $1(1): 1-6$

14. Harimurti S, Rahmah AU, Omar AA, Thanapalan M (2013) Kinetics of methyldiethanolamine mineralization by using UV/ $\mathrm{H}_{2} \mathrm{O}_{2}$ process. Clean 41(12): 1165-1174

15. Durán-Moreno A, García-González S, Gutiérrez-Lara M, Rigas F, Ramírez-Zamora R (2011) Assessment of Fenton's reagent and ozonation as pre-treatments for increasing the biodegradability of aqueous diethanolamine solutions from an oil refinery gas sweetening process. J Hazard Mater 186(2):1652-1659

16. Soleymani AR, Saien J, Bayat H (2011) Artificial neural networks developed for prediction of dye decolorization efficiency with UV/K $\mathrm{K}_{2} \mathrm{~S}_{2} \mathrm{O}_{8}$ process. Chem Eng J 170(1):29-35

17. Kurechi T, Aizawa M, Kunugi A (1983) Studies on the antioxidants XVIII: oxidation product of tertiary butyl hydroquinone (TBHQ)(I). J Am Oil Chem Soc 60(11):1878-1882

18. Hepel M, Luo J (2001) Photoelectrochemical mineralization of textile diazo dye pollutants using nanocrystalline WO3 electrodes. Electrochim Acta 47(5):729-740

19. Lau TK, Chu W, Graham NJ (2007) The aqueous degradation of butylated hydroxyanisole by $\mathrm{UV} / \mathrm{S}_{2} \mathrm{O}_{8}{ }^{2-}$ : study of reaction mechanisms via dimerization and mineralization. Environ Sci Technol 41(2):613-619
20. Salari D, Niaei A, Aber S, Rasoulifard MH (2009) The photooxidative destruction of CI Basic Yellow 2 using $\mathrm{UV} / \mathrm{S}_{2} \mathrm{O}_{8}{ }^{2-}$ process in a rectangular continuous photoreactor. J Hazard Mater 166(1):61-66

21. Weiner ER (2000) Applications of environmental chemistry: a practical guide for environmental professionals. CRC Press, Boca Raton

22. Ahmadi M, Behin J, Mahnam AR (2013) Kinetics and thermodynamics of peroxydisulfate oxidation of Reactive Yellow 84. J Saudi Chem Soc (article in pess)

23. Rasoulifard MH, Majidzadeh H, Demneh FT, Babaei E, Rasoulifard MH (2012) Photocatalytic degradation of tylosin via ultraviolet-activated persulfate in aqueous solution. Int $\mathrm{J}$ Ind Chem 3(1):1-5

24. Roig B, Gonzalez C, Thomas O (1999) Measurement of dissolved total nitrogen in wastewater by UV photooxidation with peroxodisulphate. Anal Chim Acta 389(1):267-274

25. Chu W, Lau TK, Fung SC (2006) Effects of combined and sequential addition of dual oxidants $\left(\mathrm{H}_{2} \mathrm{O}_{2} / \mathrm{S}_{2} \mathrm{O}_{8}{ }^{2-}\right)$ on the aqueous carbofuran photodegradation. $\mathrm{J}$ Agric Food Chem 54(26): 10047-10052

26. Anipsitakis GP, Dionysiou DD (2003) Degradation of organic contaminants in water with sulfate radicals generated by the conjunction of peroxymonosulfate with cobalt. Environ Sci Technol 37(20):4790-4797

27. Anipsitakis GP, Dionysiou DD (2004) Radical generation by the interaction of transition metals with common oxidants. Environ Sci Technol 38(13):3705-3712

28. Saien J, Soleymani A (2007) Degradation and mineralization of Direct Blue 71 in a circulating upflow reactor by $\mathrm{UV} / \mathrm{TiO}_{2}$ process and employing a new method in kinetic study. J Hazard Mater 144(1):506-512

29. Salari D, Daneshvar N, Niaei A, Aber S, Rasoulifard M (2008) The photo-oxidative destruction of CI Basic Yellow 2 using UV/ $\mathrm{S}_{2} \mathrm{O}_{8}{ }^{2-}$ process in an annular photoreactor. J Environ Sci Health A 43(6):657-663

30. Liang CJ, Bruell CJ, Marley MC, Sperry KL (2003) Thermally activated persulfate oxidation of trichloroethylene (TCE) and 1,1,1-trichloroethane (TCA) in aqueous systems and soil slurries. Soil Sediment Contam 12(2):207-228

31. Chan TW, Graham NJD, Chu W (2010) Degradation of iopromide by combined UV irradiation and peroxydisulfate. J Hazard Mater 181(1-3):508-513

32. Minisci F (1975) Free-radical additions to olefins in the presence of redox systems. Acc Chem Res 8(5):165-171

33. Modirshahla N, Behnajady M, Ghanbary F (2007) Decolorization and mineralization of CI Acid Yellow 23 by Fenton and photoFenton processes. Dyes Pigm 73(3):305-310

34. Rasoulifard MH, Marandi R, Majidzadeh H, Bagheri I (2011) Ultraviolet light-emitting diodes and peroxydisulfate for degradation of basic red 46 from contaminated water. Environ Eng Sci 28(3):229-235

35. Lin C-C, Wu M-S (2014) Degradation of ciprofloxacin by UV/ $\mathrm{S}_{2} \mathrm{O}_{8}{ }^{2-}$ process in a large photoreactor. J Photochem Photobiol, A 285:1-6

36. Bautista P, Mohedano AF, Gilarranz MA, Casas JA, Rodriguez JJ (2007) Application of Fenton oxidation to cosmetic wastewaters treatment. J Hazard Mater 143(1-2):128-134

37. Sun S-P, Li C-J, Sun J-H, Shi S-H, Fan M-H, Zhou Q (2009) Decolorization of an azo dye Orange $\mathrm{G}$ in aqueous solution by Fenton oxidation process: effect of system parameters and kinetic study. J Hazard Mater 161(2-3):1052-1057

38. Qiao R-P, Li N, Qi X-H, Wang Q-S, Zhuang Y-Y (2005) Degradation of microcystin-RR by UV radiation in the presence of hydrogen peroxide. Toxicon 45(6):745-752 
39. Khataee AR, Mirzajani O (2010) UV/peroxydisulfate oxidation of C. I. Basic Blue 3: modeling of key factors by artificial neural network. Desalination 251(1-3):64-69

40. Behnajady M, Modirshahla N, Fathi H (2006) Kinetics of decolorization of an azo dye in UV alone and $\mathrm{UV} / \mathrm{H}_{2} \mathrm{O}_{2}$ processes. J Hazard Mater 136(3):816-821

41. Lee Y-C, Lo S-L, Kuo J, Lin Y-L (2012) Persulfate oxidation of perfluorooctanoic acid under the temperatures of $20-40{ }^{\circ} \mathrm{C}$. Chem Eng J 198:27-32

42. Hayon E, McGarvey JJ (1967) Flash photolysis in the vacuum ultraviolet region of sulfate, carbonate, and hydroxyl ions in aqueous solutions. J Phys Chem 71(5):1472-1477
43. Xu S-C, Zhou H-D, Wei X-Y, Lu J (1989) The pH dependence and effects of the oxidative products of some aromatic compounds in ozonation under irradiation. Ozone sci Eng 11(3):281-296

44. Saien J, Asgari M, Soleymani A, Taghavinia N (2009) Photocatalytic decomposition of direct red 16 and kinetics analysis in a conic body packed bed reactor with nanostructure titania coated Raschig rings. Chem Eng J 151(1):295-301 